This is the final peer-reviewed accepted manuscript of:

De Luigi, N., Gibertoni, D., Randon, E., \& Scorcu, A. E. (2018). Patterns of gambling activities and gambling problems among Italian high school students: Results from a latent class analysis. Journal of Gambling Studies, 34(2), 339-359.

The final published version is available online at:

https://doi.org/10.1007/s10899-017-9694-2

Rights / License:

The terms and conditions for the reuse of this version of the manuscript are specified in the publishing policy. For all terms of use and more information see the publisher's website.

This item was downloaded from IRIS Università di Bologna (https://cris.unibo.it/)

When citing, please refer to the published version. 


\title{
Patterns of Gambling Activities and Gambling Problems Among Italian High School Students: Results from a Latent Class Analysis
}

\author{
Nicola De Luigi ${ }^{1}$ Dino Gibertoni ${ }^{2}$ - Emanuela Randon ${ }^{3}$. \\ Antonello E. Scorcu ${ }^{3}$
}

\begin{abstract}
This study aims to provide an estimate of the prevalence of gambling among Italian adolescents and a description of their patterns of gambling activities (PGAs) using a latent class analysis on 13 different types of games. A nationwide sample of 10,959 Italian high school students was recruited in 2013. We assessed problem gambling using the South Oaks Gambling Screen: Revisited for Adolescent (SOGS-RA) scale. Approximately half $(50.6 \%)$ of students reported gambling at least once in the previous year; $5.0 \%$ of them were problem gamblers and $9.1 \%$ were at-risk gamblers according to their SOGS-RA scores. Eight PGAs were identified, among which heavy players (1.7\% of students) could be classified as problem gamblers and broad skill players $(2.0 \%)$ and lotteries \& sports players $(2.4 \%)$ as "at-risk" players. These high-risk classes were consistently associated with risky behaviours in terms of substance use, school performance, money spent on gambling and family environment; the other five classes identified low-risk players associated with safe behaviours. To the best of our knowledge, this is the first study to identify PGAs among Italian adolescents. Problem gamblers are not a homogeneous group in terms of patterns of gambling activities and are associated with different risk factors, among which environmental factors, such as parents' gambling attitude and behaviour, deserve
\end{abstract}

\author{
Dino Gibertoni \\ dino.gibertoni2@unibo.it \\ Nicola De Luigi \\ nicola.deluigi@unibo.it \\ Emanuela Randon \\ emanuela.randon@unibo.it \\ Antonello E. Scorcu \\ antonello.scorcu@unibo.it \\ 1 Department of Sociology and Business Law, University of Bologna, Strada Maggiore 45, \\ 40125 Bologna, Italy \\ 2 Department of Biomedical and Neuromotor Sciences, University of Bologna, Via San Giacomo 12, \\ 40126 Bologna, Italy \\ 3 Department of Economics, University of Bologna, Strada Maggiore 45, 40125 Bologna, Italy
}


special attention. The acknowledgment of such patterns and risk factors could be useful in developing sensible public policies addressing prevention strategies and regulatory instruments.

Keywords Adolescent gambling · Patterns of gambling · Problem gambling · Latent class analysis - SOGS-RA

\section{Introduction}

Gambling is nowadays a common leisure activity among adolescents. Despite the adoption of legal constraints and controls on entering gambling venues, in many countries the likelihood of adolescents becoming active gamblers has increased because of the expansion of legalized gambling sites, the introduction of new types of games based on always more sophisticated technology and the pervasive advertising of gambling on the media (Derevensky and Gupta 2000; Volberg et al. 2010). Large-scale prevalence studies carried out in Europe, the United States (US), Australia and Canada have shown gambling rates among adolescent populations ranging between 60 and 90\% (Calado et al. 2016; Molde et al. 2009; Räsänen et al. 2015; Turner et al. 2008; Welte et al. 2008; Yip et al. 2011). In Italy, two recent nationwide surveys found the proportion of adolescents involved in gambling to be smaller than in the aforementioned countries, i.e. $46.8 \%$ in Colasante et al. (2014) and 44\% in Molinaro et al. (2014), but still reaching a remarkable prevalence.

Given these high participation rates, there has been a growing concern about adolescents' gambling and its consequences (Derevensky and Gilbeau 2015; Gupta and Derevensky 2000; LaBrie and Shaffer 2007). The main findings from existing studies have shown that adolescents with gambling problems or pathologies are still a small subgroup of the total young gambler population, ${ }^{1}$ but they are at a higher risk of developing gambling disorders than adults. The negative effects resulting from gambling disorders during adolescence (such as disrupted relationships, poor school performance, school drop-out, criminal records) often seriously affect young people's adult life (Delfabbro et al. 2016; Derevensky and Gupta 2004; Kristiansen and Jensen 2011; Molde et al. 2009; Volberg et al. 2010). Various risk factors associated with problem/pathological gambling among adolescents have been identified, related to individual demographic characteristics, social aspects, personality traits, attitudes and beliefs (Hanss et al. 2014). Gambling-related problems are more common among males than females (Boldero et al. 2010; Gausset and Jansbøl 2009; Welte et al. 2009). Family and peer gambling histories and socioeconomic status (Shaffer et al. 2004; Vitaro et al. 2004) crucially influence the development of gambling attitudes. A large body of evidence has revealed that initial gambling experiences often originate in adolescents' own environments through playing with family members and that strong parental and/or peer gambling and gambling approval are usually associated with more serious adolescent gambling disorders. Adolescents' gambling problems are also frequently associated with poor family cohesion and low parental supervision.

Gupta and Derevensky (1998) observed that adolescent gambling can be considered a way to escape daily problems in parental relationships and/or friendships. Whereas the identification of causal relations is difficult (Blinn-Pike et al. 2010; Gori et al. 2014;

1 A review of youth gambling studies across three continents (Australia, Europe and North America) found that $2-13 \%$ of youth meet diagnostic criteria for problem gambling (Volberg et al. 2010). 
Johansson et al. 2009), engagement in other addictive behaviours (such as smoking, drinking and drug use) and disruption in familial and personal relationships have been associated with adolescent problem gamblers. The presence of school problems, such as poor performance and truancy, was also associated to gambling problems (Floros et al. 2015; Splevins et al. 2010; Winters et al. 1993, 2002), but little is known about the different types of negative experiences in school resulting from gambling.

The specific gambling activity constitutes an important factor associated with problem gambling (Marshall and Wynne 2004; Scalese et al. 2016). Gambling is a label used to refer to a range of activities related to stimulation and is associated with different char-acteristics shaping the players' experience (Dickerson 1993). Several studies concerning the adult population have suggested that the type of gambling activity is relevant in problem gambling. As problem gambling is associated with high frequency events, games promoting rapid gambling and the immediacy of response, machine gambling is considered the most problematic type (Breen and Zimmerman 2002; Dowling et al. 2005). However, these studies were focused on treated adult populations and lacked any standardized assessment of problem gambling; similar evidence regarding adolescents is still lacking. The relationships between specific forms of gambling and problem gambling need to be interpreted considering not only how often gamblers engage in a specific activity, but also how many games they play (Afifi et al. 2014; LaPlante et al. 2011; Lund 2006; Welte et al. 2009) and in which combinations. This point is crucial for analysing gambling involvement, particularly for adolescents as they often do not limit themselves to a single gambling activity, but have a tendency to try, also simultaneously, different kinds of gambling games (Welte et al. 2009). In this regard, Studer et al. $(2016,423)$ suggested that "it may not be a specific activity per se that drives individuals to be more likely to experience gambling problems, but rather some specific patterns of gambling activities", namely the actual gambling activities in which adolescents are engaged. Furthermore, these patterns can substantially change over time, as habits develop, and from country to country, according to institutional arrangements and/or cultural traditions.

The analysis of the association between specific patterns of gambling and gambling problems among young people and adolescents is still limited (Engwall et al. 2004; Griffiths 2000; Griffiths et al. 2009; Welte et al. 2007). Three studies overcame the lim-itations highlighted above by identifying different patterns of gambling activities (PGAs) among adolescents using latent class analysis (LCA): Goudriaan et al. (2009) identified different patterns of gambling activities among a sample of US college students, whereas Boldero et al. (2010) focused on Australian high school students and Studer et al. (2016) considered young Swiss males. As for Italy, few studies have been carried out on Italian adolescents to analyse their gambling behaviour (Gori et al. 2014; Volberg et al. 2010), but to the best of our knowledge none have identified their PGAs.

The primary objective of this study was to estimate the gambling prevalence among Italian adolescents and to identify their PGAs in order to investigate, using a large nationwide sample collected among high school students, the activities in which adolescents gamblers are involved. The PGAs were then examined in terms of their association with gambling problems, tobacco, alcohol and drug use/abuse, family environment and with school conduct and performance. Lastly, a comparison with the PGAs found in other international studies on adolescents gambling was carried out. 


\section{Materials and Methods}

\section{Procedure and Participants}

The data source for the study was the survey "Gioco e Giovani", designed to monitor the gambling attitudes and behaviours of Italian high school students. Promoters of the survey are Nomisma (an economics research institute based in Bologna) and the University of Bologna, Department of Economics jointly with the Department of Sociology and Business Law. Schools were randomly selected among public high schools of all types (technical and vocational schools and scientific, linguistic, classical, artistic and human sciences lyceums) in all Italian regions. In each school at least one class was randomly selected for every grade. Students were asked to complete an anonymized web-based questionnaire using their schools' laboratory facilities. The administration of the questionnaire was authorized by the schools' deans and student participation was voluntary. The survey was carried out during the spring semester in 2014, following a pilot test in the autumn/winter of 2013. In total, 11,414 questionnaires were compiled, of which 455 (3.99\%) were excluded due to incoherent or incomplete data, thus resulting in a final study population of 10,959 students.

\section{Measures}

The questionnaire was structured in four sections: (1) gambling attitudes, motivation and activities; gambling activities of friends and family; (2) personal well-being, including leisure activities and substance use (legal and illegal drugs, cigarettes, alcohol, energy drinks); (3) school status and performance (type of college, achievement scores and personal satisfaction in school attendance); (4) socio-economic characteristics of family members (social and cultural status, religious attitudes, place of birth, type of employment and level of education).

Participants were asked the frequency of play and the amount of money spent in the previous 12 months on 13 different items of gambling games, comprising gambling machines (video lotteries and slot machines), lottery playing (lotto, scratch cards, bingo, national lottery, SuperEnalotto), different types of sport betting, online betting (using the internet, smartphone and tablet), online poker or casino, other online skill games. The frequency of use of each gambling item was recorded using a 5-point Likert scale, graded "never", "rarely", "about once a month", "about once a week", "about every day". The same scale was used to assess the frequency of gambling activities of adolescents' family and peers. The amount of money spent on gambling by adolescents was examined using an 8-point scale graded from less than 3 euros a week to more than 90 euros a week, which was then aggregated in 3 classes: $<3$ euros, 3-10 euros, $>10$ euros a week. Participants were also asked if they had parents, relatives, friends or acquaintances who had declared bankruptcy because of gambling.

Gambling-related problems were assessed using the South Oaks Gambling Screen: Revised for Adolescents (SOGS-RA) (Langhinrichsen-Rohling et al. 2004; Winters et al. 1993). We applied the narrow criteria suggested by Winters et al. (1995) to obtain three severity groups: a score of 4 or greater was associated with "problem gambling", a score of 2-3 identified "at risk" subjects and a score of 0-1 indicated "no problem". A study published at the same time as the administration of our survey found the SOGS-RA to be a reliable and valid instrument for the assessment of problem gambling in a sample of Italian 
students (Colasante et al. 2014). Individual awareness of the addictive potential of gambling was also assessed.

Participants were asked on a 5-point scale, ranging from "daily" to "never", how many times in the previous 12 months they had used substances (cigarettes, wine, beer, hard drinks, energy drinks, medicines and drugs).

Overall school performance rated on a 1-10 scale and the frequency of truancy were self-reported by participants. Age, sex, geographic area, living situation (with both parents or just one of them) were measured, along with specific items investigating the parents' level of education and the occupational status and immigrant background of each parent.

\section{Statistical Analysis}

The demographic and social characteristics of study participants and the scale scores were summarized as mean $\pm \mathrm{SD}$, median and interquartile range and percentages where appropriate.

Latent Class Analysis was used to obtain subgroups of students sharing similar patterns of involvement in gambling activities. Specifically, we identified the gambling pattern subgroups using LCA over 13 dichotomous variables related to the gambling items and obtained by aggregating the four levels of playing reported in the previous year. Using LCA, each individual was univocally assigned to one group, not based on an a priori classification but as a result of his/her probability to belong to a specific class given his/her response pattern for the 13 indicators.

To determine the optimal number of groups, LCA models with an increasing number of latent classes were tested, starting from the simplest 1-group, until acceptable solutions were found. We considered the concurrent fulfilment of the following conditions: a relative frequency of each latent class of at least 1\%; significant values for the bootstrapped likelihood ratio test (BLRT) (McLachlan 1987) and the (Vuong)-Lo-Mendell-Rubin (LMR) likelihood ratio test (Lo et al. 2001) or the adjusted LMR (ALMR) likelihood ratio test. BLRT, LMR and ALMR compare model fit improvements between the current n-class LCA model and the $n-1$ model. A significant $p$ value for the test statistics indicates that the current model has a significantly better fit than the $n-1$ latent class model. Moreover, model fit indices were compared, namely the Akaike information criterion (AIC; Akaike 1973), the Bayesian information criterion (BIC; Schwarz 1978) and the adjusted BIC (ABIC; Sclove 1987), with lower values indicating a better model fit. To determine the optimal number of latent classes, BLRT and BIC are the best performing among these measures, as shown by simulation studies (Nylund et al. 2007). The choice of the optimal model among those identified was made by taking into account the model fit and the usefulness and the ease of interpretation of the different solutions.

We assessed the quality of the LCA solution by examining the average latent class probabilities for most likely latent class membership. These probabilities measure the rate of correct classification of individuals in the latent classes, which could be low when many individuals have similar probabilities of being assigned to two or more different latent classes. Following Nagin (2005), an acceptable classification is obtained when the correct assignment for every latent class is $\geq 0.70$.

The groups found using LCA were interpreted and labelled by comparing the probabilities of engagement in the 13 games that were used as indicators for the LCA. The association between class membership and problematic gambling was evaluated by calculating the proportions of SOGS-RA severity groups in each class. Subsequently, to provide a more detailed description of the groups, bivariate analyses were carried out 
comparing the socio-demographic characteristics of students across the LCA groups. Finally, following Boldero et al. (2010), we investigated whether the amount of money spent across the different gambling patterns was associated with an increased likelihood of problematic gambling. This analysis was conducted using an analysis of covariance in which the continuous SOGS-RA score was the dependent variable, the latent class was the group factor and weekly expenditure was the covariate, including the interaction between gambling patterns and the amount gambled.

Mplus 7.4 was used for LCA estimation and Stata 13.1 for descriptive and inferential analyses.

\section{Results}

As summarized in Table 1, the students in the study population were on average 16.2 years old, with a predominance of males $(53.6 \%)$ and the majority residing in Northern Italy (59.2\%). About half of the participants $(5542,50.6 \%)$ had gambled in the previous 12 months, playing 3.3 different gambling activities on average. Among the 5542 players, $67.0 \%$ reported almost daily activity, 552 (5.0\% of students, $10.0 \%$ of players) were classified as "problem gamblers" and 999 (9.1 and 18.0\% of students and players) were "at risk" according to the SOGS-RA scores. Only 3.5\% of participants declared that gambling has no addictive potential. Regarding substance use, around $15 \%$ of students reported drinking wine, spirits and energy drinks at least weekly, with the figure rising to $24.9 \%$ for beer, but a lower frequency for drugs (6.7\%). Daily smokers numbered $19.0 \%$.

The participants predominantly attended technical schools $(47.4 \%)$, while lyceums and vocational schools accounted for $36.6 \%$ and $15.5 \%$ respectively. The self-reported overall and mathematic grades were on average above the pass mark (respectively 6.91 and 6.59); $26.3 \%$ of participants reported at least one unexcused absence from school in the previous 12 months. About $20 \%$ of students were from families with a low educational background and $15 \%$ were from families with at least one immigrant parent.

Based on the LCA fit indices (Table 2), the six- to nine-class models were examined to determine the optimal solution. The nine-class model had the best AIC and ABIC and was also supported by the BLRT test; however, it was discarded because one of its classes included only $0.8 \%$ of cases. The seven-class model had the best BIC value, but the interpretation of its gambling pattern looked awkward. The eight-class model was finally preferred over the six-class model in consideration of its higher informative insight and better fit statistics. The quality of the assignment of individuals to classes was very good: the average probabilities for most likely latent class membership were at least equal to 0.82 , with the exception of classes 3 and 4 , which showed a partial overlap, and the entropy index was 0.813 .

The first class included $12.2 \%$ of subjects (Table 3 ), who had a high probability of being engaged in sports betting and sports pools, thus it was called sports gamblers. The second class had a lower prevalence $(4.0 \%)$ and comprised lottery gamblers, who played luck games, such as lotteries and scratch cards. The third class (13.6\% of the participants) included subjects who were almost exclusively engaged in scratch card games. The fourth class $(6.6 \%)$ was, as indicated by the assignment probabilities, quite similar to the third. Despite playing online skill games in addition to scratch cards, this was still a low-problem class, suggesting that some members of this group were possibly not-for-money players of online solitaire games. Thus, we called the third class scratch card players and the fourth 
Table 1 Description of the study population $(\mathrm{n}=10,959)$

\begin{tabular}{|c|c|c|}
\hline Age (mean, SD) & 16.22 & 1.59 \\
\hline \multicolumn{3}{|l|}{ Age classes (n, \%) } \\
\hline$\leq 15$ & 4047 & 36.9 \\
\hline $16-17$ & 4291 & 39.2 \\
\hline$\geq 18$ & 2621 & 23.9 \\
\hline Sex, males (n, \%) & 5872 & 53.6 \\
\hline \multicolumn{3}{|l|}{ Geographic area $(\mathrm{n}, \%)$} \\
\hline Northern Italy & 6487 & 59.2 \\
\hline Central Italy & 1614 & 14.7 \\
\hline Southern Italy & 2858 & 26.1 \\
\hline \multicolumn{3}{|l|}{ Gambling } \\
\hline Players (n, \%) & 5542 & 50.6 \\
\hline Number of games (mean, SD) & 3.00 & 2.49 \\
\hline \multicolumn{3}{|l|}{ Frequency $^{\mathrm{a}}(\mathrm{n}, \%)$} \\
\hline Daily & 3714 & 67.0 \\
\hline Weekly & 762 & 16.4 \\
\hline Monthly & 911 & 13.7 \\
\hline Less than monthly & 155 & 2.8 \\
\hline \multicolumn{3}{|l|}{ SOGS-RA $^{\mathrm{a}}(\mathrm{n}, \%)$} \\
\hline No problem & 3991 & 72.0 \\
\hline At risk & 999 & 18.0 \\
\hline Problem gambling & 552 & 10.0 \\
\hline \multicolumn{3}{|l|}{ Substance use (n, \%) } \\
\hline \multicolumn{3}{|l|}{ Tobacco } \\
\hline Daily smokers & 2035 & 19.0 \\
\hline Non-smokers & 6315 & 58.8 \\
\hline Wine, at least weekly & 1671 & 15.6 \\
\hline Beer, at least weekly & 2675 & 24.9 \\
\hline Spirits, at least weekly & 1788 & 16.7 \\
\hline Energy drinks, at least weekly & 1504 & 14.0 \\
\hline Drugs, at least weekly & 718 & 6.7 \\
\hline \multicolumn{3}{|l|}{ School } \\
\hline \multicolumn{3}{|l|}{ Type of school: (n, \%) } \\
\hline Professional & 1673 & 15.5 \\
\hline Technical & 5099 & 47.4 \\
\hline Lyceum & 3941 & 36.6 \\
\hline Other & 50 & 0.5 \\
\hline Overall performance (mean, SD) & 6.91 & 1.5 \\
\hline Truancy (n, \%) & 2877 & 26.3 \\
\hline \multicolumn{3}{|l|}{ Family } \\
\hline Immigrant background (n, \%) & 1638 & 15.1 \\
\hline \multicolumn{3}{|l|}{ Parents' education (n, \%) } \\
\hline Low & 2172 & 20.0 \\
\hline Average & 5323 & 49.1 \\
\hline No. of games played in family (mean, SD) & 2.7 & 2.5 \\
\hline
\end{tabular}




\begin{tabular}{llr}
\hline Knew people ruined by gambling (n, \%) & & \\
$\quad$ None & 6178 & 56.5 \\
Relatives & 594 & 5.4 \\
Acquaintances & 3316 & 30.3 \\
Friends & 854 & 7.8 \\
Gambling leads to addiction (n, \%) & & \\
$\quad$ Yes & 8999 & 84.1 \\
Yes, less seriously & 1326 & 12.4 \\
No & 375 & 3.5 \\
\hline
\end{tabular}

${ }^{a}$ Players only

Table 2 Fit indices and $p$ values for the LCA solutions from 2 to 9 classes

\begin{tabular}{|c|c|c|c|c|c|c|c|}
\hline & AIC & BIC & ABIC & $\begin{array}{l}p \text { value for } \\
\text { LMR }\end{array}$ & $\begin{array}{l}p \text { value for } \\
\text { ALMR }\end{array}$ & $\begin{array}{l}p \text { value for } \\
\text { BLRT }\end{array}$ & Entropy \\
\hline 2 classes & $78,709.2$ & $78,906.3$ & $78,820.5$ & $<0.001$ & $<0.001$ & $<0.001$ & 0.852 \\
\hline 3 classes & $75,063.8$ & $75,363.1$ & $75,232.9$ & $<0.001$ & $<0.001$ & $<0.001$ & 0.844 \\
\hline 4 classes & $73,467.3$ & $73,868.9$ & $73,694.1$ & $<0.001$ & $<0.001$ & $<0.001$ & 0.829 \\
\hline 5 classes & $72,694.0$ & $73,197.9$ & $72,978.6$ & $<0.001$ & $<0.001$ & $<0.001$ & 0.810 \\
\hline 6 classes & $72,301.5$ & $72,907.6$ & $72,643.8$ & 0.0092 & 0.0094 & $<0.001$ & 0.812 \\
\hline 7 classes & $71,978.9$ & $72,687.3$ & $72,379.0$ & $<0.001$ & $<0.001$ & $<0.001$ & 0.821 \\
\hline 8 classes & $71,886.5$ & $72,697.0$ & $72,344.3$ & 0.0017 & 0.0018 & $<0.001$ & 0.813 \\
\hline 9 classes & $71,810.8$ & $72,723.5$ & $72,326.4$ & 0.3335 & 0.3358 & $<0.001$ & 0.828 \\
\hline
\end{tabular}

leisure players. The fifth class had the lowest prevalence (1.7\%), but the highest probability of gambling on all games and thus we called their members heavy gamblers. The sixth class included a small proportion of adolescents $(2.4 \%)$ who declared they participated with medium to high probability in a broad number of games, with peaks for sports betting, sports pools and all lotteries. Thus, they are termed lottery \& sports players. The seventh class (broad skill players, $2.0 \%$ of participants) was in contrast to the sixth because these adolescents were particularly engaged in online poker, online betting and sports betting, but had a relatively low engagement in lotteries and scratch cards. Finally, the eighth class was the largest $(57.5 \%)$ and included individuals who reported an extremely low probability of engagement in any game (rare players).

According to the SOGS-RA severity group classification, heavy players were in the majority $(50.6 \%)$ problem gamblers and the broad skill player classification contained more than $30 \%$ of both problem and at-risk subjects. All the other classes were in the majority composed of no problem students; however, the lottery \& sports class included remarkable proportions of problem (18.8\%) and at-risk (26.7\%) players. Bivariate analyses relating students' characteristics and behaviours to latent class memberships are shown in Table 4. As a general pattern, these associations are consistent with the increasing severity of problem gambling highlighted by the SOGS-RA risk scores. In particular, the frequency of substance use (tobacco, alcohol, drugs) is higher among heavy, broad skill and lottery \& sports players; moreover, students in these classes reported lower school proficiency, 
Table 3 Number and percentage of participants in each latent class, probabilities for each gambling activity as a function of latent class membership and distribution of SOGS-RA

\begin{tabular}{|c|c|c|c|c|c|c|c|c|}
\hline & \multicolumn{8}{|c|}{ Latent class } \\
\hline & $\begin{array}{l}1 . \\
\text { Sports }\end{array}$ & $\begin{array}{l}2 . \\
\text { Lottery }\end{array}$ & $\begin{array}{l}\text { 3. Scratch } \\
\text { cards }\end{array}$ & $\begin{array}{l}4 . \\
\text { Leisure }\end{array}$ & $\begin{array}{l}5 . \\
\text { Heavy }\end{array}$ & $\begin{array}{l}\text { 6. Lottery } \\
\text { \& sports }\end{array}$ & $\begin{array}{l}7 . \\
\text { Broad } \\
\text { skill }\end{array}$ & 8. Rare \\
\hline $\begin{array}{l}\text { Latent class } \\
\text { prevalence (n, } \\
\%)\end{array}$ & $\begin{array}{l}1333 \\
(12.2)\end{array}$ & $\begin{array}{l}440 \\
(4.0)\end{array}$ & $\begin{array}{l}1485 \\
(13.6)\end{array}$ & $\begin{array}{l}726 \\
(6.6)\end{array}$ & $\begin{array}{l}183 \\
(1.7)\end{array}$ & $266(2.4)$ & $\begin{array}{l}220 \\
(2.0)\end{array}$ & $\begin{array}{l}6306 \\
(57.5)\end{array}$ \\
\hline Online betting & 0.265 & 0.059 & 0.000 & 0.048 & 0.885 & 0.361 & 0.766 & 0.004 \\
\hline Online poker & 0.155 & 0.056 & 0.000 & 0.138 & 0.975 & 0.161 & 0.822 & 0.005 \\
\hline Online casino & 0.006 & 0.021 & 0.000 & 0.031 & 0.944 & 0.025 & 0.502 & 0.001 \\
\hline $\begin{array}{l}\text { Other online skill } \\
\text { games }\end{array}$ & 0.272 & 0.355 & 0.136 & 0.629 & 0.941 & 0.477 & 0.615 & 0.028 \\
\hline $\begin{array}{l}\text { Slot machines, } \\
\text { video lottery }\end{array}$ & 0.121 & 0.148 & 0.038 & 0.190 & 0.872 & 0.348 & 0.516 & 0.000 \\
\hline Super Enalotto & 0.061 & 0.931 & 0.164 & 0.076 & 0.974 & 0.852 & 0.286 & 0.004 \\
\hline Scratch cards & 0.543 & 0.965 & 0.915 & 0.629 & 0.961 & 0.959 & 0.694 & 0.027 \\
\hline Lottery & 0.034 & 0.740 & 0.093 & 0.040 & 0.989 & 0.745 & 0.256 & 0.001 \\
\hline Sports pools & 0.464 & 0.114 & 0.043 & 0.077 & 0.968 & 0.823 & 0.524 & 0.008 \\
\hline Bingo & 0.046 & 0.156 & 0.061 & 0.162 & 0.848 & 0.259 & 0.400 & 0.004 \\
\hline $\begin{array}{l}\text { Sports betting } \\
\text { (betting shop) }\end{array}$ & 0.826 & 0.151 & 0.113 & 0.000 & 0.923 & 0.938 & 0.765 & 0.055 \\
\hline $\begin{array}{l}\text { Horse betting } \\
\quad \text { (betting shop) }\end{array}$ & 0.121 & 0.019 & 0.009 & 0.001 & 0.806 & 0.337 & 0.343 & 0.001 \\
\hline National lotteries & 0.025 & 0.343 & 0.033 & 0.052 & 0.773 & 0.484 & 0.163 & 0.000 \\
\hline \multicolumn{9}{|l|}{$\begin{array}{l}\text { SOGS-RA severity } \\
\text { groups }(\%)\end{array}$} \\
\hline Problem $(4+)$ & 11.9 & 8.2 & 3.8 & 5.6 & 50.6 & 18.8 & 30.9 & 5.6 \\
\hline At risk (2-3) & 21.2 & 20.1 & 11.4 & 16.9 & 22.5 & 26.7 & 33.6 & 16.7 \\
\hline $\begin{array}{l}\text { No problem } \\
(0-1)\end{array}$ & 66.9 & 71.7 & 84.8 & 77.5 & 26.9 & 54.5 & 35.5 & 77.7 \\
\hline
\end{tabular}

higher truancy and a higher amount of money spent on gambling. In their families, gambling frequency was higher, as were the proportion of relatives who had serious gambling problems and the incidence of non-Italian parents. In contrast, students classified as rare players or scratch card players generally reported better living conditions and safer behaviours. Finally, male students were considerably more prevalent $(>82 \%)$ in the three sports-related classes and among heavy players (76.5\%). Age differed significantly among the groups, with broad skill, sports and heavy players being the oldest groups; however all age differences were relatively small in absolute value.

The money spent weekly on gambling proved to be a predictor of problem gambling after the analysis of covariance (Table 5), with a relationship differentiated across gambling patterns. In this analysis, we evaluated the main effects of gambling patterns at the lowest value of monetary expenditure (less than 3 euros a week) and the main effects of monetary expenditure for the rare player class. As for gambling patterns, we found that 


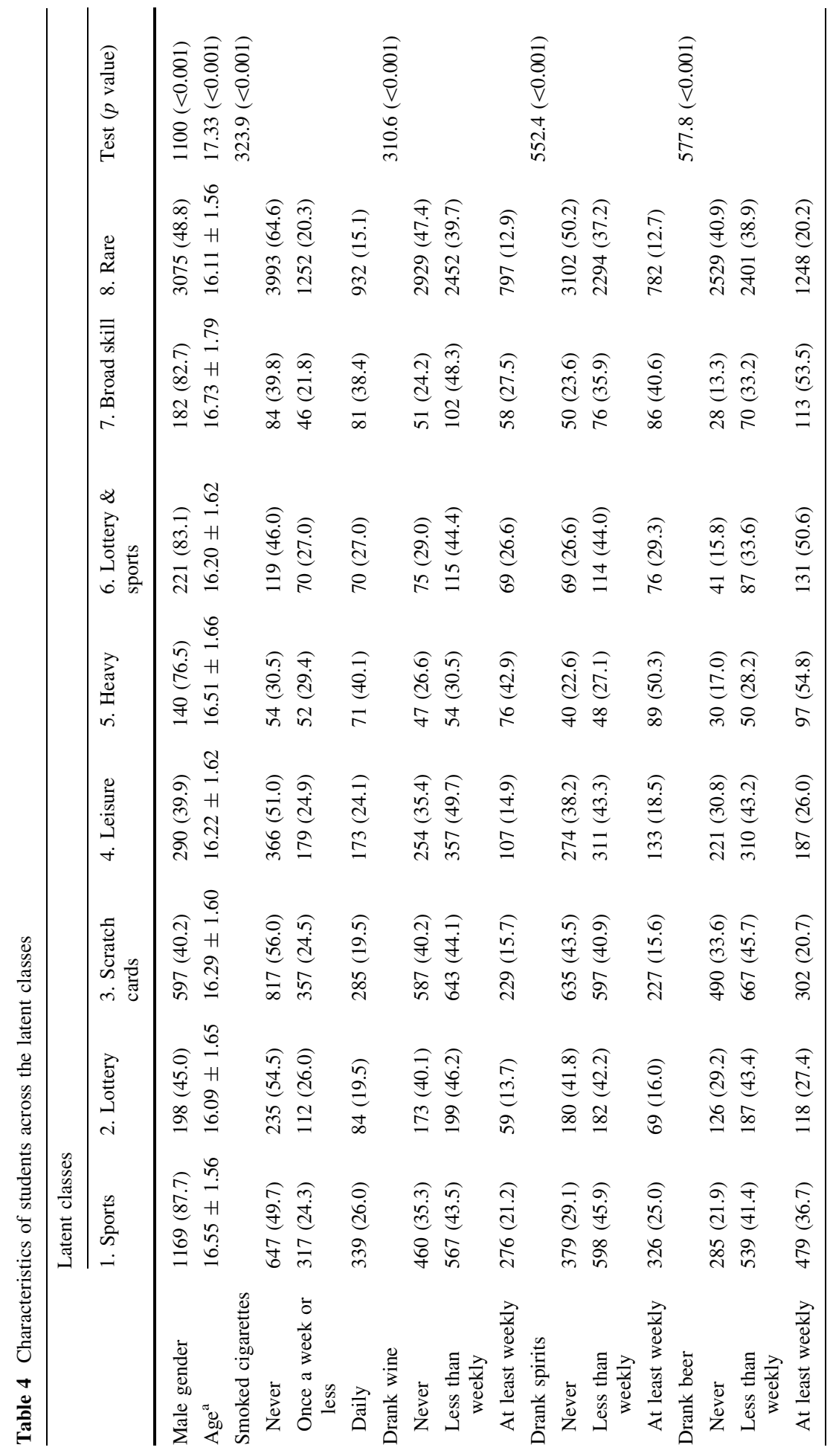




\begin{tabular}{|c|c|c|c|c|c|c|c|c|}
\hline & & $\begin{array}{l}\widehat{\hat{o}} \\
\dot{\mathrm{v}} \\
\text { aे } \\
\text { \& }\end{array}$ & $\vec{z}$ & & 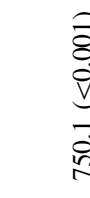 & 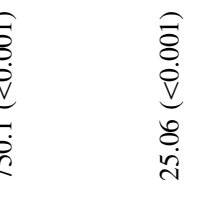 & 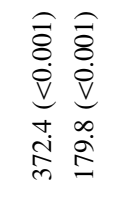 & $\begin{array}{l}\widehat{\bar{\sigma}} \\
\dot{\dot{\theta}} \\
\stackrel{8}{o} \\
\dot{j}\end{array}$ \\
\hline & & 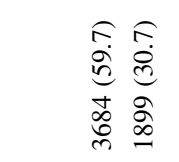 & $\begin{array}{l}0 \\
\dot{g} \\
\dot{a} \\
0 \\
b\end{array}$ & 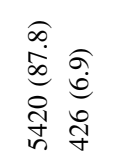 & 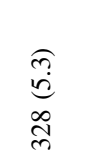 & 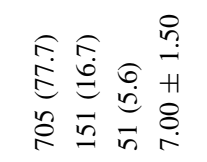 & 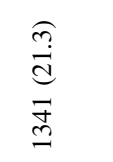 & 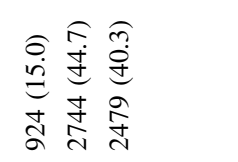 \\
\hline & & 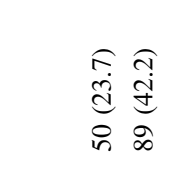 & 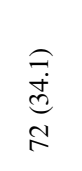 & 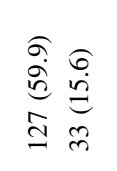 & $\begin{array}{l}\sqrt[n]{a} \\
d \\
\text { ind } \\
\text { in }\end{array}$ & 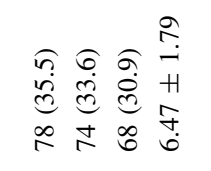 & $\begin{array}{l}\underset{i}{0} \\
\text { d. } \\
\stackrel{0}{=}\end{array}$ & 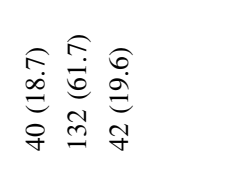 \\
\hline & 要 & 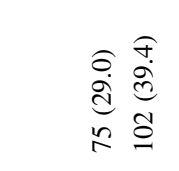 & $\begin{array}{l}\underset{0}{0} \\
\underset{\infty}{2} \\
\infty\end{array}$ & 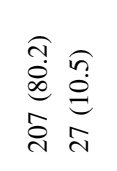 & $\begin{array}{l}\widehat{a} \\
\vec{d}\end{array}$ & 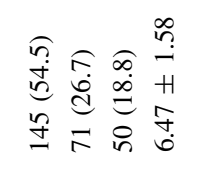 & $\begin{array}{l}\stackrel{\widehat{J}}{d} \\
\stackrel{J}{\Xi}\end{array}$ & 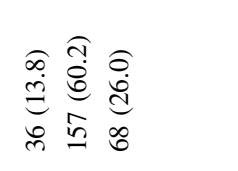 \\
\hline & $\stackrel{s}{x}$ & 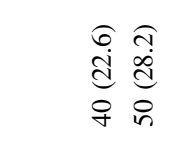 & 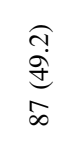 & 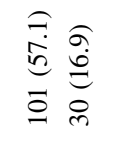 & 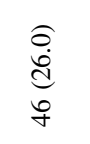 & 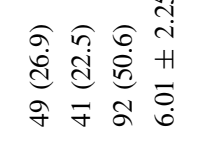 & 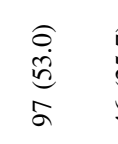 & 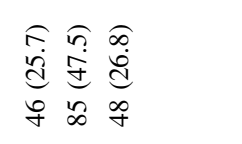 \\
\hline & $\frac{\underbrace{\frac{0}{2}}_{0}}{2}$ & 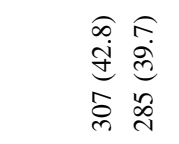 & $\begin{array}{l}\mathfrak{n} \\
\stackrel{2}{0} \\
\end{array}$ & 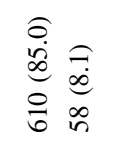 & $\begin{array}{l}a \\
\stackrel{0}{\dot{D}} \\
\text { in }\end{array}$ & 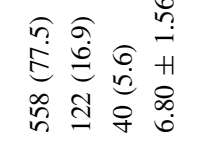 & 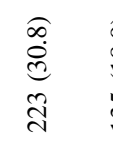 & 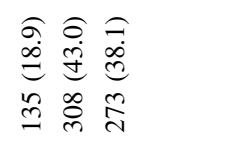 \\
\hline & 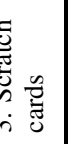 & 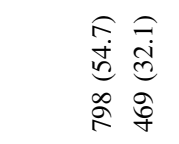 & 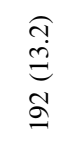 & 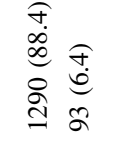 & 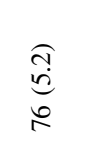 & 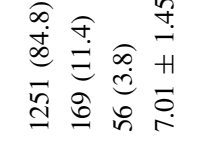 & 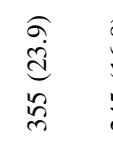 & 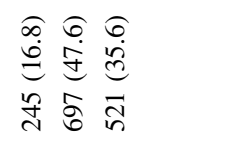 \\
\hline & 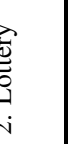 & 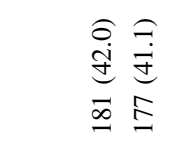 & 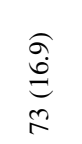 & 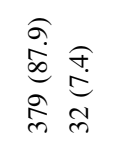 & $\begin{array}{l}\hat{\sigma} \\
\dot{+} \\
\text { ¿ें }\end{array}$ & 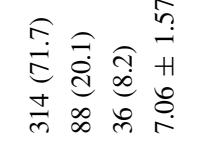 & 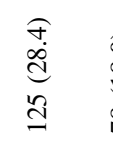 & 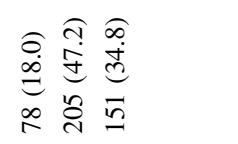 \\
\hline 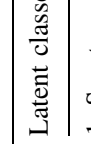 & $\frac{L_{0}^{0}}{2}$ & 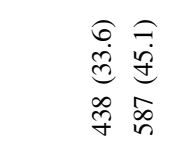 & 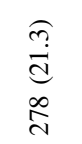 & 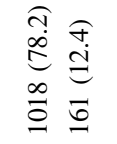 & 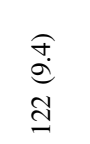 & 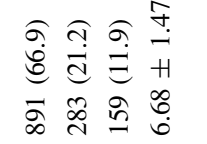 & 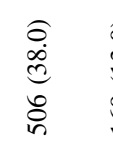 & 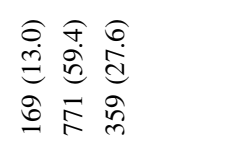 \\
\hline & & 总 & $\frac{\vec{x}}{4}$ & & & & & 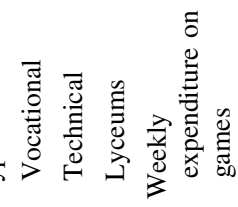 \\
\hline
\end{tabular}




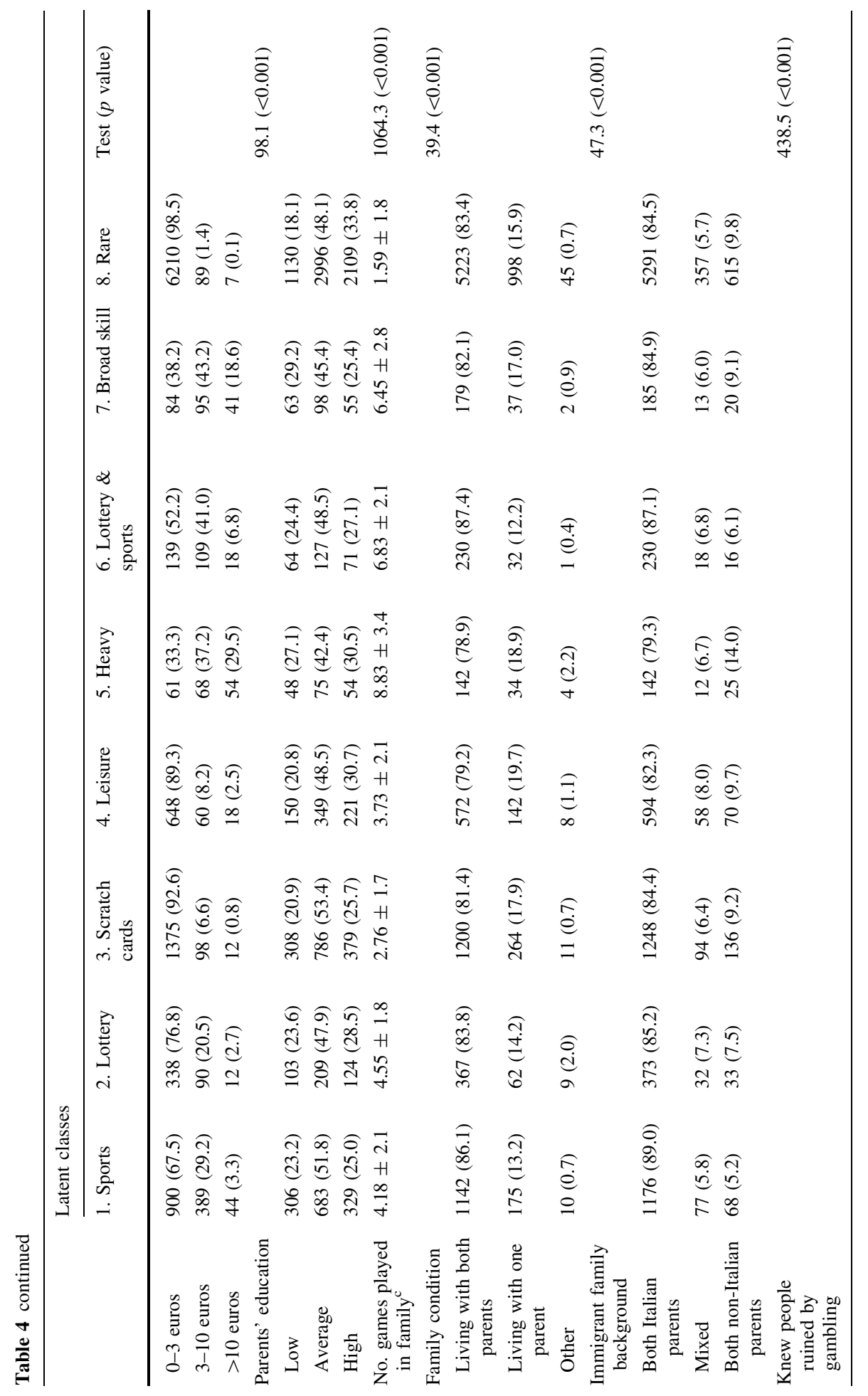




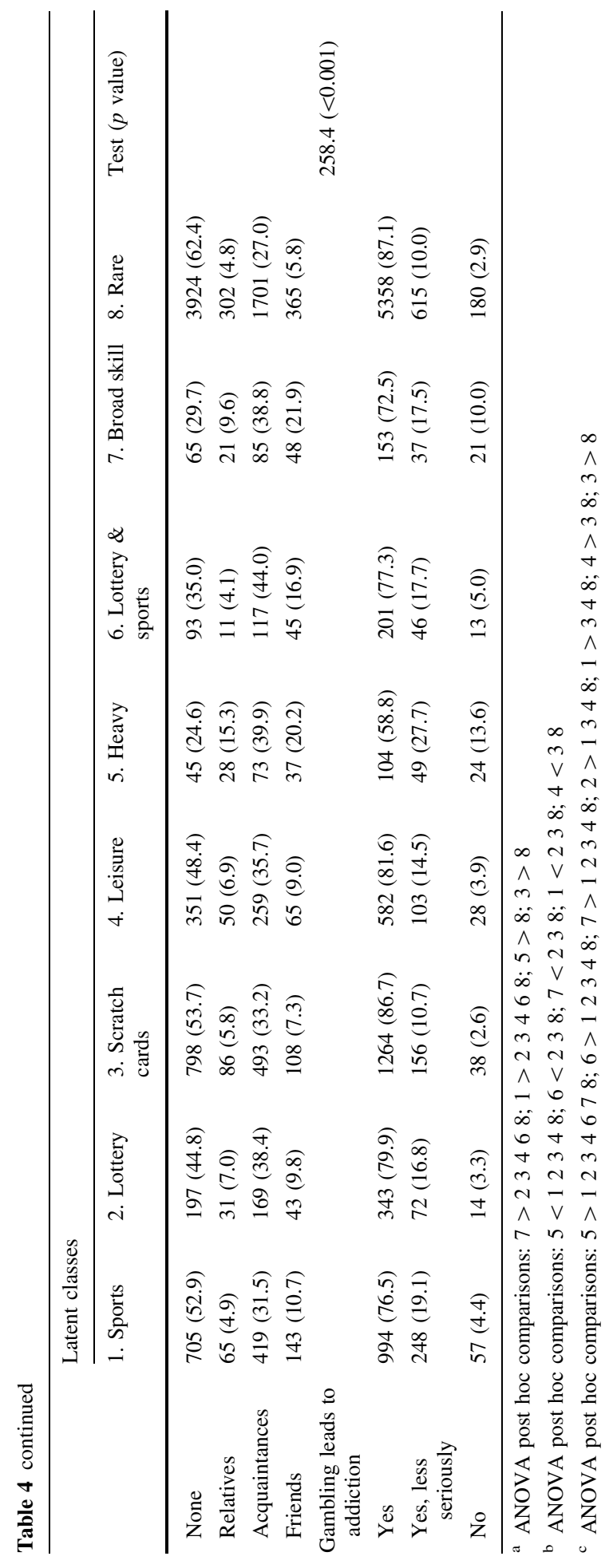


Table 5 Prediction of SOGSRA scores by gambling patterns and weekly expenditure on gambling. Main effects and interactions

\begin{tabular}{llrrr}
\hline & Coeff. & $p$ value & $95 \%$ CI & \\
\hline Gambling pattern & & & & \\
Sport & -0.179 & 0.199 & -0.451 & 0.094 \\
Lottery & 0.443 & 0.011 & 0.101 & 0.784 \\
Scratch card & -0.490 & $<0.001$ & -0.765 & -0.214 \\
Leisure & 0.159 & 0.288 & -0.135 & 0.453 \\
Heavy & 1.989 & $<0.001$ & 1.549 & 2.429 \\
Lottery \& sports & 0.250 & 0.248 & -0.174 & 0.673 \\
Broad skill & 1.003 & $<0.001$ & 0.586 & 1.420 \\
Rare & Ref. & & & \\
Weekly expenditure & 0.485 & $<0.001$ & 0.320 & 0.649 \\
Interaction & & & & \\
Sport & 0.353 & $<0.001$ & 0.163 & 0.543 \\
Lottery & -0.209 & 0.073 & -0.438 & 0.020 \\
Scratch card & 0.238 & 0.027 & 0.027 & 0.450 \\
Leisure & -0.131 & 0.227 & -0.342 & 0.081 \\
Heavy & 0.027 & 0.785 & -0.169 & 0.224 \\
Lottery \& sports & 0.274 & 0.026 & 0.033 & 0.516 \\
Broad skill & 0.108 & 0.296 & -0.095 & 0.312 \\
Constant & 0.316 & 0.004 & 0.099 & 0.533 \\
\hline & & & &
\end{tabular}

three groups (heavy, broad skill and lottery players) were positively associated with problem gambling, while membership of the scratch card player category predicted a lower SOGS-RA score. As expected, financial expenditure was also associated with a higher problem gambling risk score. From the results of the interaction among PGAs and expenditure we found that for sport $(\beta=0.35, p<0.001)$, lottery \& sports $(\beta=0.27$, $p=0.026)$ and scratch card players $(\beta=0.24, p=0.027)$, an increase in weekly expenditure on gambling was related to a further significant increase in the problem gambling score. In contrast, for subjects classified in the two highest risk classes (heavy and broad skill players), problem gambling was independent of the amount of money spent.

\section{Discussion}

Adolescent gambling in Italy has been studied only in the last decade and is a rapidly growing phenomenon. This study, based on a large nationwide sample of high school students collected in 2014, confirms that gambling is a popular activity among adolescents. We found a $50.6 \%$ prevalence of adolescent gamblers, higher than the estimates obtained in the ESPAD surveys on Italian high school students conducted using partially comparable scales in 2011 (46.8\%) and 2013 (44\%) (Colasante et al. 2014; Molinaro et al. 2014). In comparison with these studies, the rate of problem and at-risk gambling is lower: 5.0 and $9.1 \%$ ( 7.8 and $14.8 \%$ in 2011 and 7.5 and $11.6 \%$ in 2013, respectively). Our latter fig-ures suggest the presence of a decreasing trend in problem and at-risk gambling, possibly induced by the prevention measures aimed at reducing the risks associated with gambling introduced in Italian high schools since 2008 (Gori et al. 2014). 
Our study also proposes a classification of students in homogeneous groups with respect to their PGAs and provides an analysis of the association of these groups with gamblingrelated problems, social-environmental factors and other risk behaviours. Adolescent and young adult gambling patterns have been illustrated in some international studies (Boldero et al. 2010; Goudriaan et al. 2009; Studer et al. 2016), but research on Italian adolescents was still lacking. Using LCA, we have identified eight PGAs, differing in terms of family environment and parental gambling behaviour, substance (tobacco, alcohol, drug) use/ abuse, academic performance and school conduct.

The largest group (57.5\% of participants) is composed of rare players, i.e. students who declared they had never or very rarely played any game in the previous year. They showed a low probability of problem gambling and reported low use of tobacco, alcohol and other substances, good school performance and high family status. Moreover, gambling in their familiar environments had the lowest prevalence among all groups, as did familiarity with people who experienced severe gambling problems.

In contrast, the group of heavy players shows a high probability of being involved in every type of game. This is the smallest group (1.7\% of participants), with more than half $(50.6 \%)$ of their members classified as problem gamblers and an additional $22.5 \%$ showing at-risk behaviour. Moreover, they declared the highest rates of tobacco, alcohol and other substance use and the lowest school proficiency. Heavy players also had a positive attitude toward gambling - largely failing to understand the related risks - and were significantly associated with heavy parental gambling. As suggested by Hardoon and Derevensky (2002), gambling is something of a "family affair" because adolescent players report having begun gambling with parents or siblings in their home. They consider it part of their normal and accepted family social entertainment, modelling themselves on and emulating their parents and older siblings (Griffiths and Wood 2000; Ladouceur et al. 1998). Our research confirms this evidence, showing that a family environment in which gambling is rarely practised may be considered a potential protective mechanism as it does not encourage children to gamble and does not facilitate their access to gambling products. On the other hand, adolescents in families in which gambling is widely practised are more likely to become gamblers and experience problem gambling (Delfabbro and Thrupp 2003). This does not mean that a child living with a parent who is seriously involved in gambling activities will necessarily acquire a similar gambling attitude and behaviour. Indeed, other findings have shown that individuals exposed to parents' heavy gambling may develop a form of resilience through positive adaptation within the context of sig-nificant adversity favoured by a combination of protective factors, such as family cohesion, mentor relationships, school connectedness, achievement motivation and involvement in conventional organizations (Dickson et al. 2008; Shead et al. 2010).

The other six LCA classes identify different patterns of specialized gambling, involving single or several types of games. Among the broad skill players (2.0\% of participants), about one-third of members were classified as problem gamblers and one-third as at-risk players. They reported the highest tobacco, alcohol and other substance use after heavy players, as well as low school performance and living in an environment favourable to gambling; this revealed by the second largest value for parental involvement in gambling activities, a high proportion of relatives and friends with serious gambling problems (close to that of heavy players) and a positive attitude toward gambling. They were characterized by a high probability of playing casino games, betting online and offline and playing slot machines. The combination of casino gambling with other gambling activities has been found to be a high-risk profile in previous studies, much more harmful than casino gambling alone (Franco et al. 2011) and mostly associated with problem gambling for youth in 
the US (Welte et al. 2007, 2009). Griffiths and Wood (2000) highlighted the high potential addictive power of slot machines due to a combination of technological aspects and structural characteristics (event frequency, the "near miss" phenomenon, symbol ratio proportions, light and sound effects, the suspension of judgment), which may encourage individuals to play and/or to continue playing.

Another small but potentially troublesome group is that of lottery \& sports players (2.4\% of students), which includes $45 \%$ of members classified as problem or at-risk players. They differ in terms of game patterns from the lottery group (4.0\% of students) because they have a much higher probability of being involved in widely popular forms of gambling, such as sports betting, sports pools, horse betting and online betting. And they differ from sports players $(12.2 \%)$ because of their higher probability of also playing lottery games (lotteries, bingo, scratch cards). Thus, while sports games and lotteries are not found to be related to problem gambling and do not show a strong association with other addictive behaviours or with negative school behaviour when played singly, in combination they result in a risk profile. However, lottery \& sports players reported safer behaviours than heavy and broad skill players, especially regarding tobacco, spirits and other substance use, suggesting that, although showing higher SOGS-RA scores, their social behaviour does not appear to differ much from that of the other not-at-risk groups.

Scratch card players (13.6\%) displayed the best SOGS-RA scores, albeit they usually showed a higher association than rare players with other addictive behaviours (tobacco, alcohol and other substance use), higher rates of family involvement in gambling and more difficulty in school, especially truancy. The same associations were higher for leisure players $(6.6 \%)$, which nonetheless showed a distribution of SOGS-RA values almost identical to those of rare players.

It seems quite clear that some of the reported behaviours are correlated with PGAs that represent a greater risk of developing serious gambling problems: adolescents in the highrisk groups (heavy, broad skill and lottery \& sports) experienced worse school performance and higher truancy rates than rare, scratch card and leisure players (low-risk groups). Students attending lyceums are found to be more likely to be associated with lowrisk gambling profiles, while students attending technical schools are associated with PGAs in which gambling in the sports category is a prominent feature. Vocational schools show the highest proportion of heavy players. Our results therefore confirm that students with problem gambling suffer academic misbehaviour and failure in school performance (Floros et al. 2015; Splevins et al. 2010; Winters et al. 1993, 2002).

In line with previous studies, the classes of low-risk gamblers are characterized mainly by females (Boldero et al. 2010; Gausset and Jansbøl 2009; Welte et al. 2009), reporting lower weekly expenditure on games and being of a lower age. These findings are consistent with other studies that have focused on gender differences, albeit using different analytical frameworks and instruments. In particular, males have been found to be characterized by beginning gambling earlier than females, engaging in more activities, spending more money and experiencing more gambling-related problems (Jacobs 2000).

We have also shown that students in high-risk groups are more prone to engage in other risky behaviours such as smoking, drinking and drug use/abuse. However, our study design did not allow us to establish whether there is a cause-effect relationship and we acknowledge that "some of these behaviours are the result of excessive gambling, while for others gambling is used as a way of minimizing and distracting the individual from other personal problems" (Derevensky 2012, 61).

Similarly, this study finds familiarity with gambling among adolescents' relatives and peers to be higher and awareness of the addictive potential of gambling lower among the 
high-risk groups. As mentioned above, this suggests that environmental factors, such as the gambling practices of relatives and peers and the lack of youth and parental awareness concerning the risks associated with gambling may play a relevant role in the onset of gambling-related problems. As a consequence, any effective prevention of adolescent problem behaviour associated with socially acceptable risky activities, such as gambling, needs to address adolescents' social networks, aiming in particular to raise awareness among parents and other adults involved concerning the risks of gambling for youth (Derevensky et al. 2005). If parents remain reluctant to recognize their role in the development of gambling problems in their children, it will be more difficult to carry out coping strategies aimed at preventing further progression.

The relationship between weekly expenditure on gambling activities and gambling patterns is straightforward: more than $50 \%$ of adolescents classified in the high-risk groups spent at least 3 euros per week on gambling, while in the low-risk groups this figure stands below 10\%; also, after adjusting for the PGAs, expenditure retains a positive effect in relation to problem gambling. The interaction between expenditure and PGAs reveals some interesting associations: for the two highest risk groups (heavy and broad skill players), expenditure makes no additional contribution to the SOGS-RA score, while this contribution is positive and significant in two low-risk groups (sports and scratch card players) and in the lottery \& sports group. In the former case, taking into account also the level of involvement in gambling by adolescents' families reported by those classified in high-risk patterns, this finding may suggest that their gambling practices may often be sustained economically by their family members. For the low-risk groups, our findings suggest that differentiated levels of risk may exist even within some of the safest patterns, which can be revealed by the highest expenditure. This association emerges for the lottery \& sports group, which also shows a peculiar dynamic among the high-risk groups in this respect.

The PGAs that we identified through LCA share several similarities with the findings of previous studies that applied the same method to identify gambling patterns among adolescents (Boldero et al. 2010; Goudriaan et al. 2009; Studer et al. 2016). The rare and heavy player groups have been found in all studies. Rare players were the largest or normative group in Goudriaan et al. (2009) and Studer et al. (2016), with a prevalence of 50-60\% and a low probability of developing problem gambling or using tobacco, alcohol or drugs. The heavy player group was identified by Boldero et al. (2010) and was similar to the extensive gambling group proposed by Goudriaan et al. (2009) and Studer et al. (2016). In all studies, this was one of the smallest groups and was characterized by the highest probability of gambling problems and heavy use of tobacco, alcohol and drugs. The lottery and scratch card player groups were also found, separately or as a combination, in Boldero et al.'s (2010) and Studer et al.'s (2016) studies, in which they showed a similar low-risk profile and relatively healthy behaviour to rare players. The lottery \& sports group then seems a novel pattern that combines two widely popular typologies of gambling, which has always attracted people's imagination. Both typologies have experienced important transformations in recent years, not least due to the increased accessibility of advanced technologies and social media. Among the major new features are undoubtedly the possibility of providing instant feedback to players, i.e. the immediate result for some types of lottery and the real-time update of odds for sports betting. Consistently with previous findings, we found that youths playing lottery in combination with another gambling activity (sport betting in our study, casino gambling (Studer et al. 2016) or card gambling (Goudriaan et al. 2009) showed riskier profiles in terms of gambling attitudes, substance use and family environment with respect to those who only played lottery or sport betting. The stronger attraction to gambling and the higher reported level of risk with respect to the 
lottery and sport classes suggest that the lottery \& sport class represents more than a mere overlap of the two single-game classes.

The large study population and its geographical distribution covering all Italian regions represent the main strengths of the study. Moreover, the extensive questionnaire administered to participants and the operational definition of gambling adopted (based on the specification of 13 different gambling activities) enabled us to shed light on several different aspects of gambling behaviour, as well as students' socio-cultural environment and school conduct, in addition to facilitating the use of LCA in the identification of gambling patterns. The main advantage of LCA is the use of latent variables, which makes it possible to group participants depending on the actual relationships found in the data. LCA therefore delivers a gambling pattern framework that should provide a more sensitive representation of actual gambling behaviour than one descending from a priori beliefs. The size of our study population and the operational definition of gambling used allow us to subdivide adolescents according to more articulated PGAs than those already known from the literature. As a result, we have identified two latent classes corresponding to novel profiles: leisure players and lottery \& sports players. This latter class is particularly interesting as it identifies a very specific profile characterized by a complex behaviour, which, due to its novelty and its relatively high risk, might deserve further careful investigation.

In terms of limitations, this is a cross-sectional study, which therefore affords no way of assessing causation with respect to the reported outcomes. However, a follow-up study is currently being undertaken, of similar scope and using a refined questionnaire. Moreover, although high school students represent the vast majority of Italian adolescents, focusing only on students may lead to an underestimation of gambling prevalence and of gamblingrelated risk behaviours because youths not attending school may be those with a higher likelihood of being involved in gambling practices.

\section{Conclusions}

In public debate in Italy-particularly in the media-gambling is often pictured as a growing threat to adolescent wellbeing. Whereas the overall picture is correct, a generic alarming approach does not distinguish between different gambling activities or consider the different consequences of their combinations. Understanding problem or at-risk behaviours associated with specific PGAs can help researchers to identify the main mechanism(s) at work in adolescent gambling in Italy and aid professionals in focusing their efforts on creating more successful prevention and treatment measures.

Therefore we deem the results of our analysis relevant in terms of health policy prescriptions as we have provided insights into the patterns of adolescent gambling activities, showing that problem gamblers are not a homogeneous group in this regard. We have found that other risky behaviours, school conduct and school performance are diversely associated with gambling patterns. Finally, we have confirmed the important role of environmental factors, especially parents' gambling attitude and behaviour, as crucial basic elements to be addressed in the development of sensible prevention strategies and regulatory instruments.

Acknowledgements This study was funded by FARB (FFBO127297), University of Bologna. We acknowledge the crucial contribution of Silvia Zucconi, (Nomisma SpA) for the development of the dataset. 


\section{Compliance with Ethical Standards}

Conflict of interest The authors declare that they have no conflict of interest.

Ethical Approval All procedures performed in studies involving human participants were in accordance with the ethical standards of the institutional and/or national research committee and with the 1964 Helsinki Declaration and its later amendments or comparable ethical standards.

\section{References}

Afifi, T. O., LaPlante, D. A., Taillieu, T. L., Dowd, D., \& Shaffer, H. J. (2014). Gambling involvement: Considering frequency of play and the moderating effects of gender and age. International Journal of Mental Health and Addiction, 12(3), 283-294.

Akaike, H. (1973). Information theory and an extension of the maximum likelihood principle. In B. Petrov \& F. Csáki (Eds.), 2nd International Symposium on Information Theory (pp. 267-281). Budapest: Akadémia Kiadó.

Blinn-Pike, L., Worthy, S. L., \& Jonkman, J. N. (2010). Adolescent gambling: A review of an emerging field of research. Journal of Adolescent Health, 47(3), 223-236.

Boldero, J. M., Bell, R. C., \& Moore, S. M. (2010). Do gambling activity patterns predict gambling problems? A latent class analysis of gambling forms among Australian youth. International Gambling Studies, 10(2), 151-163.

Breen, R. B., \& Zimmerman, M. (2002). Rapid onset of pathological gambling in machine gamblers. Journal of Gambling Studies, 18(1), 31-43.

Calado, F., Alexandre, J., \& Griffiths, M. D. (2016). Prevalence of adolescent problem gambling: A systematic review of recent research. Journal of Gambling Studies. doi:10.1007/s10899-016-9627-5.

Colasante, E., Gori, M., Bastiani, L., Scalese, M., Siciliano, V., \& Molinaro, S. (2014). Italian adolescent gambling behaviour: Psychometric evaluation of the South Oaks Gambling Screen: Revised for Adolescents (SOGS-RA) among a sample of Italian students. Journal of Gambling Studies, 30(4), 789-801.

Delfabbro, P., King, D. L., \& Derevensky, J. L. (2016). Adolescent gambling and problem gambling: Prevalence, current issues, and concerns. Current Addiction Reports, 3(3), 268-274.

Delfabbro, P., \& Thrupp, L. (2003). The social determinants of youth gambling in South Australian adolescents. Journal of Adolescence, 26(3), 313-330.

Derevensky, J. L. (2012). Teen gambling. Understanding a growing epidemic. Plymouth: Rowman \& Littlefield Publishers.

Derevensky, J. L., \& Gilbeau, L. (2015). Adolescent gambling: Twenty-five years of research. Canadian Journal of Addiction, 6(2), 4-12.

Derevensky, J. L., \& Gupta, R. (2000). Youth gambling: A clinical and research perspective. e-Gambling. The Electronic Journal of Gambling Issues, 2, 1-11.

Derevensky, J. L., \& Gupta, R. (2004). Adolescents with gambling problems: A synopsis of our current knowledge. Journal of Gambling Issues. doi:10.4309/jgi.2004.10.3.

Derevensky, J. L., Gupta, R., Messerlian, C., \& Gillespie, M. (2005). Youth gambling problems: A need for responsible social policy. In J. L. Derevensky \& R. Gupta (Eds.), Gambling problems in youth. Theoretical and applied perspectives (pp. 231-252). New York, NY: Kluwer Academic PublishersPlenum Publishers.

Dickerson, M. (1993). Internal and external determinants of persistent gambling: Problems in generalising from one form of gambling to another. Journal of Gambling Studies, 9(3), 225-245.

Dickson, L., Derevensky, J. L., \& Gupta, R. (2008). Youth gambling problems: Examining risk and protective factors. International Gambling Studies, 8(1), 25-47.

Dowling, N., Smith, D., \& Thomas, T. (2005). Electronic gaming machines: Are they the "crack-cocaine" of gambling? Addiction, 100(1), 33-45.

Engwall, D., Hunter, R., \& Steinberg, M. A. (2004). Gambling and other risk behaviors on university campuses. Journal of American College Health, 52(6), 245-256.

Floros, G., Paradisioti, A., Hadjimarcou, M., Mappouras, D. G., Karkanioti, O., \& Siomos, K. (2015). Adolescent online gambling in Cyprus: Associated school performance and psychopathology. Journal of Gambling Studies, 31(2), 367-384.

Franco, C. A., Maciejewski, P. K., \& Potenza, M. N. (2011). Past-year recreational gambling in a nationally representative sample: Correlates of casino, non-casino, and both casino/non-casino gambling. Psychiatry Research, 188(2), 269-275. 
Gausset, Q., \& Jansbøl, K. (2009). "Tell me what you play and I will tell you who you are": Values and gambling habits in two Danish universities. International Gambling Studies, 9(1), 67-78.

Gori, M., Bastiani, L., Lucchini, F., \& Gazzetti, S. (2014). Un gioco... da ragazzi? In S. Molinaro, R. Potente, \& A. Cutilli (Eds.), Consumi d'azzardo: Alchimie, normalità e fragilità: La fotografia ESPAD 2013. Milano: CE.R.CO Edizioni.

Goudriaan, A. E., Slutske, W. S., Krull, J. L., \& Sher, K. J. (2009). Longitudinal patterns of gambling activities and associated risk factors in college students. Addiction, 104(7), 1219-1232.

Griffiths, M. (2000). Scratchcard gambling among adolescent males. Journal of Gambling Studies, 16(1), 79-91.

Griffiths, M., Wardle, H., Orford, J., Sproston, K., \& Erens, B. (2009). Sociodemographic correlates of internet gambling: Findings from the 2007 British Gambling Prevalence Survey. CyberPsychology \& Behavior, 12(2), 199-202.

Griffiths, M., \& Wood, R. T. (2000). Risk factors in adolescence: The case of gambling, videogame playing, and the internet. Journal of Gambling Studies, 16(2-3), 199-225.

Gupta, R., \& Derevensky, J. L. (1998). Adolescent gambling behavior: A prevalence study and examination of the correlates associated with problem gambling. Journal of Gambling Studies, 14(4), 319-345.

Gupta, R., \& Derevensky, J. L. (2000). Adolescents with gambling problems: From research to treatment. Journal of Gambling Studies, 16(2/3), 315-342.

Hanss, D., Mentzoni, R. A., Delfabbro, P., Myrseth, H., \& Pallesen, S. (2014). Attitudes toward gambling among adolescents. International Gambling Studies, 14(3), 505-519.

Hardoon, K. K., \& Derevensky, J. L. (2002). Child and adolescent gambling behavior: Current knowledge. Clinical Child Psychology and Psychiatry, 7(2), 263-281.

Jacobs, D. F. (2000). Juvenile gambling in North America: An analysis of long term trends and future prospects. Journal of Gambling Studies, 16(2/3), 119-152.

Johansson, A., Grant, J. E., Kim, S. W., Odlaug, B. L., \& Götestam, K. G. (2009). Risk factors for problematic gambling: A critical literature review. Journal of Gambling Studies, 25(1), 67-92.

Kristiansen, S., \& Jensen, S. M. (2011). Prevalence of gambling problems among adolescents in the Nordic countries: An overview of national gambling surveys 1997-2009. International Journal of Social Welfare, 20(1), 75-86.

LaBrie, R. A., \& Shaffer, H. J. (2007). Gambling with adolescent health. Journal of Adolescent Health, 40(5), 387-389.

Ladouceur, R., Jacques, C., Ferland, F., \& Giroux, I. (1998). Parents' attitudes and knowledge regarding gambling among youths. Journal of Gambling Studies, 14(1), 83-90.

Langhinrichsen-Rohling, J., Rohde, P., Seeley, J. R., \& Rohling, M. L. (2004). Individual, family, and peer correlates of adolescent gambling. Journal of Gambling Studies, 20(1), 23-46.

LaPlante, D. A., Nelson, S. E., LaBrie, R. A., \& Shaffer, H. J. (2011). Disordered gambling, type of gambling and gambling involvement in the British Gambling Prevalence Survey 2007. European Journal of Public Health, 21(4), 532-537.

Lo, Y., Mendell, N., \& Rubin, D. (2001). Testing the number of components in a normal mixture. Biometrika, 88(3), 767-778.

Lund, I. (2006). Gambling and problem gambling in Norway: What part does the gambling machine play? Addiction Research \& Theory, 14(5), 475-491.

Marshall, K., \& Wynne, H. (2004). Against the odds: A profile of at-risk and problem gamblers. Canadian Social Trends, 11-8, 25-29.

McLachlan, G. J. (1987). On bootstrapping the likelihood ratio test statistic for the number of components in a normal mixture. Applied Statistics, 36(3), 318.

Molde, H., Pallesen, S., Bartone, P., Hystad, S., \& Johnsen, B. H. (2009). Prevalence and correlates of gambling among 16 to 19 -year-old adolescents in Norway: Personality and social sciences. Scandinavian Journal of Psychology, 50(1), 55-64.

Molinaro, S., Potente, R., \& Cutilli, A. (2014). Consumi d'azzardo: Alchimie, normalità e fragilità. La fotografia ESPAD 2013. Milano, Italy: CerCo Edizioni.

Nagin, D. (2005). Group-based modeling of development. London: Harvard University Press.

Nylund, K. L., Asparouhov, T., \& Muthén, B. O. (2007). Deciding on the number of classes in latent class analysis and growth mixture modeling: A Monte Carlo simulation study. Structural Equation Modeling, 14(4), 535-569.

Räsänen, T., Lintonen, T., \& Konu, A. (2015). Gambling and problem behavior among 14- to 16-year-old boys and girls in Finland. Journal of Gambling Issues, 31, 1-23.

Scalese, M., Bastiani, L., Salvadori, S., Gori, M., Lewis, I., Jarre, P., et al. (2016). Association of problem gambling with type of gambling among Italian general population. Journal of Gambling Studies, 32(3), 1017-1026. 
Schwarz, G. (1978). Estimating the dimension of a model. Annals of Statistics, 6(2), 461-464.

Sclove, L. S. (1987). Application of model selection criteria to some problems in multivariate analysis. Psychometrika, 52(3), 333-343.

Shaffer, H. J., LaBrie, R. A., LaPlante, D. A., Nelson, S. E., \& Stanton, M. V. (2004). The road less travelled: Moving from distribution to determinants in the study of gambling epidemiology. Canadian Journal of Psychiatry. Revue canadienne de psychiatrie, 49(8), 504-516.

Shead, N. W., Derevensky, J. L., \& Gupta, R. (2010). Risk and protective factors associated with youth problem gambling. International Journal of Adolescent Medicine and Health, 22(1), 39-58.

Splevins, K., Mireskandari, S., Clayton, K., \& Blaszczynski, A. (2010). Prevalence of adolescent problem gambling, related harms and help-seeking behaviours among an Australian population. Journal of Gambling Studies, 26(2), 189-204.

Studer, J., Baggio, S., Mohler-Kuo, M., Simon, O., Daeppen, J.-B., \& Gmel, G. (2016). Latent class analysis of gambling activities in a sample of young Swiss men: Association with gambling problems, substance use outcomes, personality traits and coping strategies. Journal of Gambling Studies, 32(2), 421-440.

Turner, N. E., Macdonald, J., Bartoshuk, M., \& Zangeneh, M. (2008). Adolescent gambling behaviour, attitudes, and gambling problems. International Journal of Mental Health and Addiction, 6(2), 223-237.

Vitaro, F., Wanner, B., Ladouceur, R., Brendgen, M., \& Tremblay, R. E. (2004). Trajectories of gambling during adolescence. Journal of Gambling Studies, 20(1), 47-69.

Volberg, R. A., Gupta, R., Griffiths, M. D., Ólason, D. T., \& Delfabbro, P. (2010). An international perspective on youth gambling prevalence studies. International Journal of Adolescent Medicine and Health, 22(1), 3-38.

Welte, J. W., Barnes, G. M., Tidwell, M.-C. O., \& Hoffman, J. H. (2008). The prevalence of problem gambling among U.S. adolescents and young adults: Results from a national survey. Journal of Gambling Studies, 24(2), 119-133.

Welte, J. W., Barnes, G. M., Tidwell, M.-C. O., \& Hoffman, J. H. (2009). The association of form of gambling with problem gambling among American youth. Psychology of Addictive Behaviors, 23(1), $105-112$.

Welte, J. W., Barnes, G., \& Wieczorek, W. (2007). Type of gambling and availability as risk factors for problem gambling: A Tobit regression analysis by age and gender. International Gambling Studies, 7(2), 183-198.

Winters, K. C., Stinchfield, R. D., Botzet, A., \& Anderson, N. (2002). A prospective study of youth gambling behaviors. Psychology of Addictive Behaviors, 16(1), 3-9.

Winters, K. C., Stinchfield, R., \& Fulkerson, J. (1993). Patterns and characteristics of adolescent gambling. Journal of Gambling Studies, 9(4), 371-386.

Winters, K. C., Stinchfield, R. D., \& Kim, L. G. (1995). Monitoring adolescent gambling in Minnesota. Journal of Gambling Studies, 11(2), 165-183.

Yip, S. W., Desai, R. A., Steinberg, M. A., Rugle, L., Cavallo, D. A., Krishnan-Sarin, S., et al. (2011). Health/functioning characteristics, gambling behaviors, and gambling-related motivations in adolescents stratified by gambling problem severity: Findings from a high school survey. The American Journal on Addictions, 20(6), 495-508. 